\title{
Study on Urbanization Quality of Northern Jiangsu Province Based on Entropy Method
}

\author{
Wang Jun ${ }^{1, a,{ }^{*}}$, Chen Jian ${ }^{2, b}$ \\ ${ }^{1}$ School of Business Huaiyin Institute of Technology, Huaian, China \\ ${ }^{2}$ School of Business Huaiyin Institute of Technology, Huaian, China \\ a1211692043@qq.com, b2946446028@qq.com \\ ${ }^{*}$ Corresponding author
}

Keywords: Urbanization, Urbanization rate, High industrial structure.

\begin{abstract}
Urbanization quality refers to a comprehensive concept that reflects the degree of urbanization in the process of urbanization relative to the quantity of urbanization. There are different evaluation and analysis methods for the measurement of urbanization quality. In this paper, entropy method is used to measure the quality of urbanization in Northern Jiangsu Province. Through horizontal and vertical comparison, the difference and imbalance of urbanization quality in five cities in Northern Jiangsu Province are analyzed and evaluated. According to the analysis results, some suggestions are put forward.
\end{abstract}

\section{Introduction}

Since 2010, urbanization has become one of the important engines to promote the social and economic development of Northern Jiangsu.The urbanization rate in Northern Jiangsu has increased from $51.8 \%$ in 2010 to $63.2 \%$ in 2018 , which has exceeded the national average level,but there are still many gaps compared with the urbanization rate of 69.6\% in 2018 in Jiangsu Province.

The quality of urbanization refers to a comprehensive concept reflecting the quality of urbanization in the process of urbanization, which is relative to the quantity of urbanization. It refers to the development quality, coordination degree and promotion efficiency of various elements of urbanization. Many scholars have put forward different index system composition and different evaluation and analysis methods for the measurement of urbanization quality. In this paper, entropy method is proposed to measure the urbanization quality of Northern Jiangsu quantitatively, and through horizontal and vertical comparison, analyze and evaluate the difference and imbalance of urbanization quality of five cities in Northern Jiangsu.

\section{Current situation of urbanization in Northern Jiangsu}

Since 2010,the urbanization of Northern Jiangsu has entered a rapid development stage, and the urbanization rate has reached 63.2\%.In 2018, the urbanization rate of Xuzhou, the highest among the five cities in Northern Jiangsu, was $65.1 \%$, which was also lower than that of Jiangsu Province; the lowest urbanization rate of Suqian was only $60 \%$, which was close to $10 \%$ lower than that of Jiangsu Province. In recent years, although the urbanization rate of Northern Jiangsu Province has maintained rapid growth, a large number of agricultural transfer population can not really integrate into the cities and towns in reality. At the same time, there are also problems such as imperfect social security system, imperfect basic public services, unbalanced development and so on. The Gini coefficient of urban residents keeps rising, so Northern Jiangsu Province should promote the development of urbanization at the same time Pay attention to the quality improvement of urbanization. 


\section{Entropy method to measure urbanization quality in Northern Jiangsu}

Entropy method to measure the urbanization quality of Northern Jiangsu mainly considers the objective weighting method to eliminate the randomness problem caused by the professional level of the empowerer when subjective weighting.

In information theory,"entropy" was used first to measure uncertainty.The entropy method used in this paper is to establish a statistical analysis method to determine the index weight by using the characteristics of "entropy",and to determine the impact of an index on the index system by calculating the "entropy" value of each index[1].In entropy method, the information represented by an index has a negative correlation with its entropy and a positive correlation with its weight.Because of the objective weighting method,entropy method has the advantages of relatively objective and reasonable measurement results, and relatively simple and clear calculation process.

Before measuring the quality of urbanization in Northern Jiangsu,we should first establish a set of scientific and reasonable measurement index system[2].According to the principles of scientificity, systematization,feasibility and comparability, this paper considers to select 15 specific indexes from population, economy,society and ecology to build the evaluation index system of urbanization quality (as shown in Table 1).

Table 1 Urbanization quality measurement index system

\begin{tabular}{|c|c|c|c|}
\hline & Index level & unit & attribute \\
\hline 1 & Urbanization rate & $\%$ & positive \\
\hline 2 & the registered urban unemployment rate & $\%$ & reverse \\
\hline 3 & Per capita disposable income of urban residents & yuan & positive \\
\hline 4 & Per capita GDP & yuan & positive \\
\hline 5 & Proportion of added value of tertiary industry in GDP & $\%$ & positive \\
\hline 6 & $\begin{array}{c}\text { Proportion of non-agricultural employees in total } \\
\text { employees }\end{array}$ & $\%$ & positive \\
\hline 7 & $\begin{array}{l}\text { Number of students in Colleges and universities per } \\
10000 \text { population }\end{array}$ & Person & positive \\
\hline 8 & Number of health technicians per 10000 people & Person & positive \\
\hline 9 & Engel coefficient of urban residents & $\%$ & reverse \\
\hline 10 & $\begin{array}{c}\text { Per capita consumption expenditure ratio of urban and } \\
\text { rural residents (rural }=1 \text { ) }\end{array}$ & ratio & moderate \\
\hline 11 & Urban population density & Person / km2 & moderate \\
\hline 12 & Economic density & $\begin{array}{l}100 \text { million yuan / } \\
\mathrm{km} 2\end{array}$ & positive \\
\hline 13 & Urban air quality excellence rate & $\%$ & positive \\
\hline 14 & $\begin{array}{l}\text { The amount of books collected by public libraries per } \\
10000 \text { population }\end{array}$ & book & positive \\
\hline 15 & Power consumption per unit of GDP & $\begin{array}{l}\text { KWh / } 10000 \\
\text { yuan }\end{array}$ & reverse \\
\hline
\end{tabular}

The main steps of applying entropy method to comprehensive evaluation can be divided into[3-4]:

Step 1:Standardize the original data.Because the indicator attributes in the indicator system are different,there are also differences in the methods of Standardization:

For positive indicators: $x_{i j}^{\prime}=\frac{x_{i j}-\min \left(x_{1 j}, x_{2 j}, \cdots x_{n j}\right)}{\max \left(x_{1 j}, x_{2 j}, \cdots, x_{n j}\right)-\min \left(x_{1 j}, x_{2 j}, \cdots, x_{n j}\right)}$;

For reverse indicators: $x_{i j}^{\prime}=\frac{\max \left(x_{1 j}, x_{2 j}, \cdots x_{n j}\right)-x_{i j}}{\max \left(x_{1 j}, x_{2 j}, \cdots, x_{n j}\right)-\min \left(x_{1 j}, x_{2 j}, \cdots, x_{n j}\right)}$;

For moderate index: $x_{i j}^{\prime}=\frac{\max \left|x_{i j}-A\right|-\left|x_{i j}-A\right|}{\max \left|x_{i j}-A\right|-\min \left|x_{i j}-A\right|}$ 
Among: $i=1,2, \cdots, n ; j=1,2, \cdots, m$;A is a moderate reference value;

Step 2:Since the value of 0 will appear in the data after standardization and affect the calculation in the next step,all values need to be translated:

$$
x_{i j}=x_{i j}^{\prime}+a, \text { Take the text } a=0.01 ;
$$

Step 3:Calculate the index $j$, the proportion of standardized data of the first $i$ measurement object in the sum of standardized data of the first $m$ measurement object:

$$
p_{i j}=\frac{x_{i j}}{\sum_{i=1}^{n} x_{i j}} ;
$$

Step 4:Calculate the entropy of the $j$ index:

$$
e_{j}=-\frac{1}{\ln n} \sum_{i=1}^{n} p_{i j} \ln p_{i j}, \text { the value of } e_{j} \text { is } 0-1 \text {; }
$$

Step 5:Calculate the coefficient of variation of index $j$, the value of $g_{j}$ is $0-1$ :

$$
g_{j}=1-e_{j}
$$

Step 6:Calculate weight:

$$
w_{j}=\frac{g_{j}}{\sum_{j=1}^{m} g_{j}} ;
$$

Step 7:Calculate the comprehensive score of each measurement object:

$$
s_{j}=100 * \sum_{j=1}^{m} w_{j} p_{i j}
$$

Next,this paper measures the entropy and weight of each index according to the entropy method described above.Table 2 shows the entropy value,variation coefficient and weight of each indicator of urbanization quality in Northern Jiangsu in 2018[5], and then calculate the comprehensive score of urbanization quality in Northern Jiangsu in 2011-2018, as shown in Figure 1[6].

Table 2 Entropy, coefficient of variation and weight of urbanization quality indicators in Northern Jiangsu in 2018

\begin{tabular}{c|c|c|c}
\hline index & $e_{j}$ & $g_{j}$ & $w_{j}$ \\
\hline Urbanization rate & 0.9944 & 0.0056 & 0.0084 \\
\hline $\begin{array}{c}\text { the registered urban unemployment rate } \\
\text { residents }\end{array}$ & 0.9989 & 0.0011 & 0.0016 \\
\hline $\begin{array}{c}\text { Per capita GDP } \\
\text { Proportion of added value of tertiary } \\
\text { industry in GDP }\end{array}$ & 0.9936 & 0.0064 & 0.0095 \\
\hline $\begin{array}{c}\text { Proportion of non-agricultural employees } \\
\text { in total employees }\end{array}$ & 0.9888 & 0.0112 & 0.0166 \\
\hline $\begin{array}{c}\text { Number of students in Colleges and } \\
\text { universities per 10000 population }\end{array}$ & 0.8399 & 0.0344 & 0.0511 \\
\hline $\begin{array}{c}\text { Number of health technicians per 10000 } \\
\text { people }\end{array}$ & 0.9956 & 0.0044 & 0.0066 \\
\hline Engel coefficient of urban residents & 0.9794 & 0.0206 & 0.0307 \\
\hline $\begin{array}{c}\text { Per capita consumption expenditure ratio } \\
\text { of urban and rural residents (rural = 1) }\end{array}$ & 0.9946 & 0.0054 & 0.0080 \\
\hline Urban population density & 0.8631 & 0.1369 & 0.2038 \\
\hline Economic density & 0.9485 & 0.0515 & 0.0767 \\
\hline $\begin{array}{c}\text { The amount of books collected by public } \\
\text { libraries per 10000 population }\end{array}$ & 0.9543 & 0.0457 & 0.0681 \\
\hline Power consumption per unit of GDP & 0.9759 & 0.0241 & 0.0359 \\
\hline
\end{tabular}




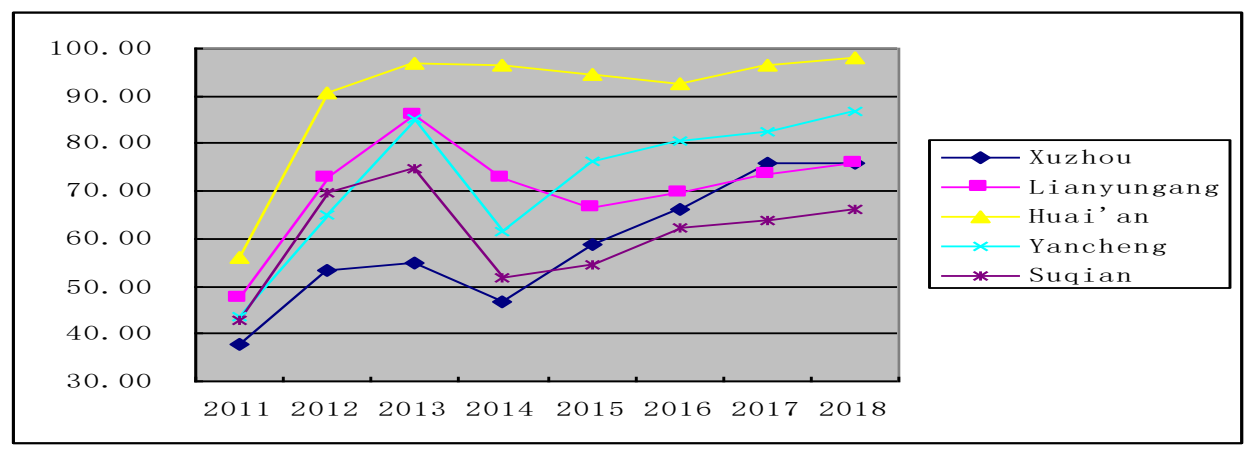

Fig. 1. Comprehensive score of urbanization quality of five cities in Northern Jiangsu from 2011 to 2018

\section{Summary}

From Figure 1 the comprehensive scores of urbanization quality of five cities in Northern Jiangsu can be seen as follows: From 2011 to 2018, the urbanization quality of the five cities in Northern Jiangsu has improved significantly, but the development level of the urbanization quality of the five cities is not balanced, but after eight years of development, the gap between the five cities has a trend of expansion; Huai'an City in the five cities is in a leading position in the development of urbanization quality, and the gap with other cities, especially Suqian City, has a trend of gradually widening. We should establish a new concept of urbanization, formulate a scientific and multi-dimensional development model, take into account the different performance of population, economy, society and ecology, not only pursue too fast economic growth, but also promote regional balanced development according to the different development levels of the five cities in Northern Jiangsu, promote coordinated development of urbanization with the strategy of urban agglomerations, and strengthen the development of urban agglomerations to urbanization The support function of. Based on the principle of intensive and compact development, low-carbon and resource conservation, we should scientifically layout the urban internal spatial structure, reasonably plan the spatial function layout of industrial area, residential area, commercial area,etc.,improve the urban economic density and population density within the scope of the comprehensive bearing capacity of the town, improve and perfect the social security system, formulate targeted policies and plans, and realize the five cities in Northern Jiangsu Balanced development of urbanization quality.

\section{References}

[1] Zhang Hongmei, Zhu Hai, Zhang Mu, etc. Evaluation of new urbanization development level of county based on relative entropy. Statistics and decision making, vol.18, pp.66-68,2018.

[2] Zhang man, Yu Siming. Evaluation of urbanization quality and analysis of regional differences based on entropy method: a case study of Hunan Province. Heilongjiang finance, vol.8, pp.65-68,2018.

[3] zhusujia, Guangxinju. Analysis on the development quality and effectiveness of County Urbanization --Taking Hebei Province as an example. Geography and geographic information science, vol.06, pp.101-105, 2017.

[4] Zhang Chunling, Wu Hongxia, Liu Zunfeng. Evaluation and selection of regional strategic emerging industries under low carbon economy. Ecological economy, vol.05, pp.132-135, 2013.

[5] Han Lei. Evaluation of green economic development in Hunan Province Based on entropy method and factor analysis. Journal of Zhongzhou University, vol.5, pp.39-42,2017. 
[6] LAN Qiong. Evaluation of the comprehensive strength of 14 cities in Guangxi Based on entropy, factor analysis and cluster analysis. Times economic and trade, vol.6,pp.209-210,2013. 